\title{
Genetic Variants Related to Cell Cycle and Stability of Telomere in Patients with Glioma
}

\author{
Maria Clara Jessica Calastri ${ }^{1 *}$, Gabriela Hattori ${ }^{1}$, Nicolas Luz Toledo Ortega \\ Rodrigues $^{2}$, Michele Lima Gregório ${ }^{1}$, Camila Ive Ferreira Oliveira Brancati ${ }^{1}$, \\ Eliane Milharcix Zanovelo ${ }^{3}$, José Roberto Lopes Ferraz Filho ${ }^{3}$, Cassiano Merussi \\ Neiva $^{4}$, Antonio Carlos Ponde Rodrigues Junior ${ }^{3}$, Moacir Fernandes de Godoy ${ }^{1}$, \\ Carmen Lucia Penteado Lancellotti ${ }^{5}$, Waldir Antonio Tognola ${ }^{6}$, Dorotéia Rossi \\ Silva Souza ${ }^{1}$
}

\begin{abstract}
Background: Glioma, most common primary malignant brain tumor in adults, is highly aggressive and associated with a poor prognosis. Evaluate the association of polymorphisms related of to the cell cycle, integrity and DNA repair with gliomas, as well as lifestyle habits, comorbidities, survival and response to treatment. Methods: Were studied 303 individuals distributed into: Study Group - 100 patients with gliomas, regardless of the degree of malignancy, and Control Group - 203 individuals without clinical signs of the disease. These polymorphisms were genotyped by TaqMan ${ }^{\circledR}$ SNP Genotyping Assay. Significance level was set at 5\%. Results: Smoking, alcohol consumption, systemic arterial hypertension ( $\mathrm{SAH}$ ) and diabetes mellitus $(\mathrm{DM})$ prevailed in patients, compared to controls $(\mathrm{P}=0.0088, \mathrm{P}=0.0001$, $\mathrm{P}=0.0001, \mathrm{P}=0.0011$, respectively). In the logistic regression analysis, alcohol consumption and $\mathrm{SAH}$ were identified as independent risk factors for gliomas $(\mathrm{P}=0.0001, \mathrm{P}=0.0027$, respectively). Patients with low-grade gliomas showed survival in one year $(92.0 \pm 6.8 \%)$, compared to patients with high-grade gliomas $(24.0 \pm 5.3 ; \mathrm{P}=0.011)$. Conclusion: Polymorphisms involved in cell cycle, telomere protection and stability and DNA repair are not associated with gliomas. On the other hand, alcohol consumption and SAH stand out as independent risk factors for the disease. Low-grade gliomas, response to treatment and the combination of chemotherapy with Temozolomide and radiation therapy show increased survival of patients.
\end{abstract}

Keywords: Glioblastoma- polymorphism- magnetic resonance spectroscopy- astrocytoma

Asian Pac J Cancer Prev, 20 (8), 2345-2351

\section{Introduction}

Gliomas are primary brain tumors of the central nervous system (CNS) and account for about $40 \%$ of all intracranial neoplasms and $80 \%$ of all malignant tumors (Zhang et al., 2016). Each year, more than 250,000 new malignant brain tumors are diagnosed worldwide. In Brazil, over 10,270 cases have been estimated in 2016 (INCA et al., 2014; Walsh et al., 2016). These tumors are classified according to the type of affected glia cells, including astrocytomas, oligodendrogliomas, oligoastrocitomas and ependymomas, which define four degrees of malignancy, i.e., gliomas of grades I and II considered as low grade, and gliomas of grades III and IV considered as high grade (Wang et al., 2015).

Smoking, alcohol consumption (Galeone et al., 2013; Hou et al., 2016), systemic arterial hypertension (SAH) and diabetes mellitus (DM) (Talacchi et al., 2013; Seliger et al., 2016), can be pointed out as risk factors for glioma carcinogenesis, as well as demographics, such as age and gender (INCA et al., 2016). Additionally, advances in molecular biology have shown diseases susceptibility genes involved in the pathophysiology, etiology, and prognosis of gliomas (Wu et al., 2016). It is important to point out the association of polymorphisms of the gene CCND1 (cyclin D1) with the development of gliomas, which plays a role in regulating the cell cycle, acting in the G1-S phase transition (Chen et al., 2015).

${ }^{1}$ Department of Biochemistry and Molecular Biology, Faculty of Medicine, São José do Rio Preto, São Paulo , ${ }^{2}$ Departament Molecular Biology on the Sao Paulo State University- "Júlio de Mesquita Filho" Campus- UNESP/IBILCE, "Departament of Patology of the Hospital de Base University Hospital of the Medical School of São José do Rio Preto - HB/FAMERP, ${ }^{4}$ Department of Physical Education of the Sao Paulo State University- "Júlio de Mesquita Filho" Campus- UNESP/Campos de Bauru. ${ }^{5}$ Department of Neurology of Santa Casa of São Paulo Medical Science College, ${ }^{6}$ Departament of Neurology of the Medical School of São José do Rio Preto - FAMERP, Brazil. *For Correspondence: mariaclarajessica@hotmail.com 
Equally important are the XRCC1 genes (X-ray repair cross complementing group 1) and RTEL1 (regulator of telomere elongation helicase 1), which play a role in repairing breakpoints in the single-strand DNA and stabilizing telomeres, respectively (Zhao et al., 2014; Zhang et al., 2016). The identification of specific biomarkers may promote new therapeutic approaches based on molecular mechanisms, contributing to early diagnosis and prognosis of patients with glioma.

In this context, the aim of this study was to evaluate the association of gene polymorphisms related to cell cycle, DNA repair and telomere structure with gliomas, as well as comorbidities, lifestyle habits, clinical profile, survival analysis and response to treatment patients with the disease.

\section{Materials and Methods}

\section{Patients}

This is a study with 293 individuals, regardless of gender, ethnicity and age. They were distributed into: Study Group (SG) - 100 patients with gliomas (1-81 y.o.; $62 \%$ males), regardless of the type and degree of malignancy (I-IV), whose samples of the brain tumor tissue were collected from 2003 to 2015 and stored in paraffin block; and Control Group (CG): 203 individuals without clinical signs of any neoplasia (7-90 y.o.; 67\% males).

All SG patients were selected after histological confirmation from blocks by the Pathology Department of Hospital de Base (University Hospital of the Medical School of São José do Rio Preto - HB/FAMERP) and their respective clinical and radiological data from medical records. An Informed Consent Document was not required, as the material had already been collected, and therefore offered no additional risks. CG individuals were selected at the HB Imaging Department, after skull MRI with negative diagnosis for gliomas, other cancers or chronic diseases. All CG individuals were informed of the characteristics of the study and confirmed their participation by signing an Informed Consent Document. They also completed a questionnaire with demographics, comorbidities and lifestyle habits, and underwent peripheral blood collection for the analysis of genetic polymorphisms. This study was approved by the Research Ethics Committee CEP/FAMERP (CAAE: 34123314.9.0000.5415).

\section{Genotyping}

The salting-out technique (Salazar et al., 1998) was used for genomic DNA extraction for $\mathrm{CG}$; for $\mathrm{SG}$, extraction was performed from samples of paraffin-embedded tissues using ReliaPrep ${ }^{\text {TM }}$ FFPE gDNAMiniprep System (Promega Biotechnology - Brazil), according to the manufacturer's instructions. Concentration and purity were analyzed in NanoDrop ${ }^{\circledR}$ ND-1000 Spectrophotometer (Thermo Scientific - USA), according to the manufacturer's instructions. The sample absorbance was measured at $260 \mathrm{~nm} / 280 \mathrm{~nm}$, considering a ratio of $1.8-2.0$ as pure. The allele distribution per polymerase chain reaction (PCR) in real time (single nucleotide polymorphism - SNP) was used for genotyping of polymorphisms of CCND1, XRCC1 and RTEL1, using TaqMan ${ }^{\circledR}$ SNP Genotyping Assays probes (Applied Biosystems - USA): CCND1 (rs9344) - C-744725_1_; XRCC1 (rs25487) - C-622564_10 and RTEL1 (rs $\overline{6} 0 \overline{1} 0620)$ - C-25921674_10, respectively. Positive and negative control for all reactions was applied with a total volume of $10 \mu \mathrm{L}$ at final concentration of 20 $n g / \mu \mathrm{L}$ of DNA. For the reaction mixture, $5 \mu \mathrm{L}$ of TaqMan ${ }^{\circledR}$ Universal PCR Master Mix (Thermo Scientific - USA), 3 $\mu \mathrm{L}$ of DEPC solution, $0.5 \mu \mathrm{L}$ of TaqMan ${ }^{\circledR}$ SNP Genotyping Assay and $1.5 \mu \mathrm{L}$ of the DNA sample were added. The samples were processed at $94^{\circ} \mathrm{C}$ for five minutes, followed by 40 cycles at $94^{\circ} \mathrm{C}$ for 10 seconds, $60^{\circ} \mathrm{C}$ for 15 seconds and $72^{\circ} \mathrm{C}$ for 15 seconds.

\section{Statistical analysis}

For the comparative analysis between the groups, the t- Test and Fisher's Exact test or Chi-square test were used for quantitative and categorical variables, respectively, as well as logistic regression to identify independent risk factors for the disease. In the evaluation of Hardy-Weinberg equilibrium, the observed and expected genotype distribution was performed using the Chi-square test. Significance level was set at 5\%. Statistical data were analyzed using the StatsDirect and Graph Pad Prism software.

\section{Results}

Smoking and drinking habits prevailed in SG (40.0\%, $47.0 \%$, respectively), compared to CG $(24.6 \% ; 16.7 \%$; $\mathrm{P}=0.0088, \mathrm{P}=0.0001$, respectively; Table 1 ). The same was true for SAH (SG: $55.0 \%$ versus CG: $27.1 \%$; $\mathrm{P}=0.0001$ ) and DM $(22.0 \%, 8.4 \%$, respectively; $\mathrm{P}=0.0011)$, whereas overweight or obesity was similar between both groups (58.9\%, 62.2\%, respectively; $\mathrm{P}=0.6421)$.

Regarding the polymorphism analysis (Table 2), the heterozygous genotype of CCND1-rs9344 (A/G) stood out in patients (41.0\%) and controls (50.2\%; $\mathrm{P}=0.1684)$, as well as the RTEL1-rs601620 (A/G - SG: 99.0\%; CG: $100.0 \%$; $\mathrm{P}=0.3311)$, with similarity of their respective alleles between both groups $(\mathrm{P}>0.05)$. For XRCC1-rs25487, the wild-type homozygous genotype (TT) prevailed in both groups (SG: 46.0\%; CG: 48.0\%; $\mathrm{P}=0.8020)$, as well as the $\mathrm{T}$ allele $(\mathrm{P}=0.5616)$. The dominant, recessive and codominant models were similar between both groups $(\mathrm{P}>0.05)$ for all polymorphisms.

The Hardy-Weinberg equilibrium was assessed for all SNPs in both groups, with genotype distributions similar to those expected for CCND1-rs9344 (SG: $\chi^{2}=2.4048 ; \mathrm{P}=0.12096$ and $\left.\mathrm{CG}: \chi^{2}=0.1357 ; \mathrm{P}=0.71251\right)$; XRCC1-rs25487 (SG: $\chi^{2}=2.7170 ; \mathrm{P}=0.09928$ and CG: $\left.\chi^{2}=2.4417 ; \mathrm{P}=0.11814\right)$; which was not observed with RTEL1-rs6010620 (SG: $\chi^{2}=\mathrm{N} / \mathrm{C} ; \mathrm{P}=\mathrm{N} / \mathrm{C}$ and CG: $\chi^{2}=203$; $\mathrm{P}=0.00000$ ). In relation to the histological grades, the genotypic distribution of these polymorphisms was performed (wild type homozygote versus allele of risk genotype). However, there were similarities between genotypes in the four histological classifications for all polymorphisms analyzed $(\mathrm{P}>0.05)$.

In the logistic regression analysis, genotypes with at 
Table 1. Distribution of Lifestyle Habits and Comorbidities in Patients with Gliomas (Study Group - SG) and Individuals without any Signs of the Disease (Control Group - CG)

\begin{tabular}{lcrrrr}
\hline Variables & \multicolumn{2}{c}{ SG } & \multicolumn{2}{c}{ CG } & P -value \\
& \multicolumn{2}{c}{$(\mathrm{N}=100)$} & \multicolumn{2}{c}{$(\mathrm{N}=203)$} & \\
& $\mathrm{N}$ & $\%$ & $\mathrm{~N}$ & $\%$ & \\
& & & & & \\
\hline Lifestyle Habits & 40 & 40 & 50 & 24.6 & 0.0088 \\
$\quad$ Smoking & 47 & 47 & 34 & 16.7 & 0.0001 \\
Alcohol Consumption & & & & & \\
Commorbities & 55 & 55 & 55 & 27.1 & 0.0001 \\
SAH & 22 & 22 & 17 & 8.4 & 0.0011 \\
Diabetes Mellitus & 58 & 58.9 & $61 *$ & 62.2 & 0.6421 \\
BMI $\geq 25 \mathrm{~kg} / \mathrm{m}^{2}$ & & & & & \\
\hline
\end{tabular}

least one risk allele were considered, as well as DM and smoking, with no significant difference $(\mathrm{P}>0.05)$. For the other variables, alcohol consumption and hypertension were identified as independent risk factors for gliomas ( $\mathrm{P}=0.0001, \mathrm{P}=0.0027$, respectively). The logistic regression equation was represented as follows: (logit $\mathrm{Y}=$ $-1.732869+1.463821$ alcohol consumption +0.883435 $\mathrm{SAH}+0.693107 \mathrm{DM})$.

The actuarial Kaplan-Meier curve assessed the survival of patients with gliomas starting on the patient's day of surgery. The survival analysis showed similarity between risk genotypes and wild-type genotype for all analyzed polymorphisms ( $\mathrm{P}>0.05$; Figure $1-\mathrm{A}$ and $\mathrm{B}$ ). The analysis of the total sample showed $18.8 \pm 5.3 \%$ of patients free-event/ death in three years (Figure 1- C). Regarding the response to treatment, the group under

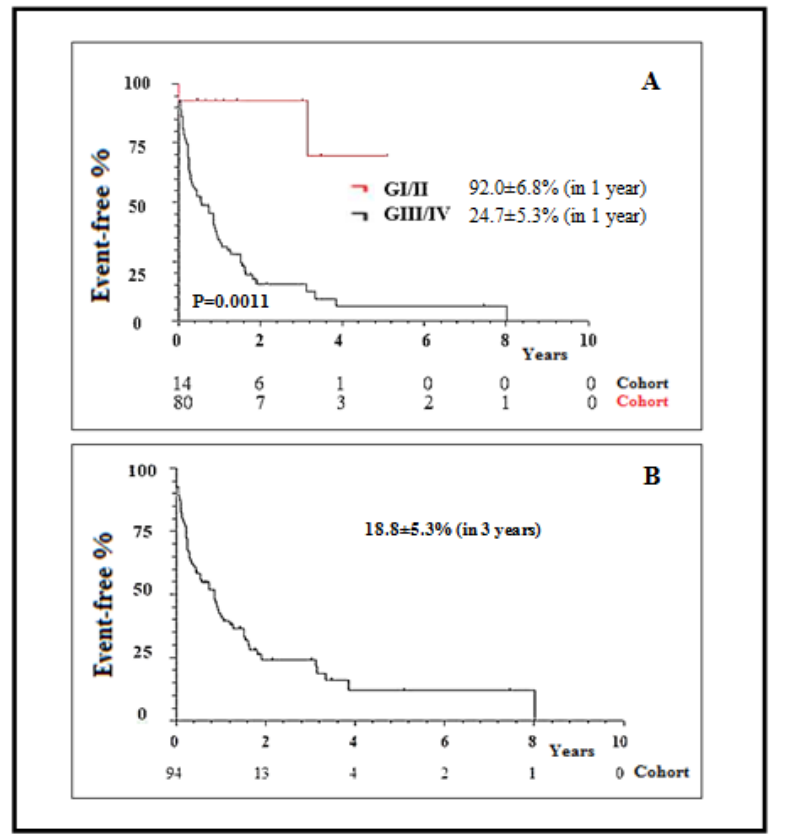

Figure 1. Actuarial Kaplan-Meier Curve for Event-Free Survival Analysis of Patients with Gliomas. *Actuarial Kaplan-Meier Curve; Log Rank Test, with significance level of $<0.05$; GI, Grade I; GII, Grade II; GIII, Grade III; GIV, Grade IV; A, Image A and B, Image B.

$\mathrm{TMZ}$ and radiation therapy showed higher prevalence of free event/death $(78.7 \pm 7.6 \%$ in 20 months), compared to those treated with TMZ $(21.9 \pm 5,1 \%$ in 20 months $)$, but with no significant difference $(\mathrm{P}>0.05$; Figure 1 - $\mathrm{D})$.

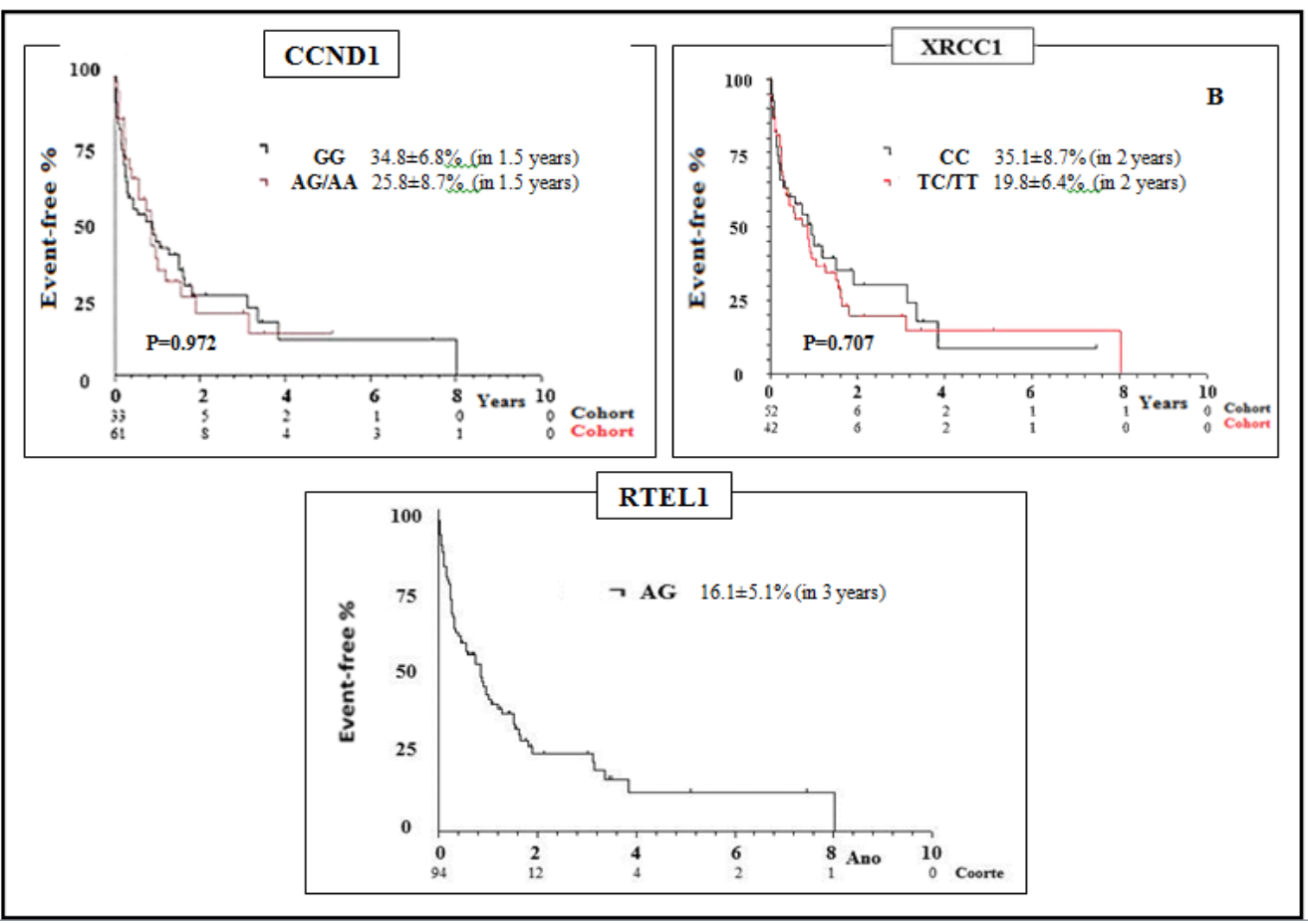

Figure 2. Kaplan-Meier Curve for Analysis of Event-Free Survival (Death) in Patients with Gliomas, Related to Genotypes; CCND1, genotype GG and AG/AA; XRCC1, genotype TT and TC/CC and RTEL1, genotype AG. *Actuarial Kaplan-Meier Curve; Log Rank Test, with significance level of $<0.05$; CCND1 = Cyclin D1; XRCC1 = $\mathrm{X}$-ray repair cross complementing group 1; RTEL1 = Regulator of telomere elongation helicase 1; $\mathrm{A}=\mathrm{Image} \mathrm{A} ; \mathrm{B}=$ Image $\mathrm{B}$ and $\mathrm{C}=$ Image $\mathrm{C}$. 
Table 2. Distribution of Genotype and Allele Frequencies of the Polymorphism of CCND1-rs9344; XRCC1-rs25487 and RTEL1-rs601620 in Patients with Gliomas (SG) and Individuals without the Disease (CG).

\begin{tabular}{|c|c|c|c|c|}
\hline Polimorfismo & Model & Genotype & SG & $\overline{C G}$ \\
\hline \multirow{9}{*}{$\begin{array}{l}C C N D 1 \\
\text { (rs9344) }\end{array}$} & Dominant & $\mathrm{G} / \mathrm{G}$ & $36(36.0)$ & $65(32.0)$ \\
\hline & OR (CI95\%) & $\mathrm{A} / \mathrm{G}+\mathrm{A} / \mathrm{A}$ & $64(54.0)$ & $138(68.0 \%)$ \\
\hline & \multicolumn{4}{|c|}{$1.12(0.80-1.56)$} \\
\hline & OR (CI95\%) & $\mathrm{A} / \mathrm{G}$ & $41(41.0)$ & $102(50.2)$ \\
\hline & Recessive & $\mathrm{G} / \mathrm{G}+\mathrm{A} / \mathrm{A}$ & $59(59.0)$ & $101(49.8)$ \\
\hline & \multicolumn{4}{|c|}{$0.77(0.55-1.08)$} \\
\hline & OR (CI95\%) & $\mathrm{A} / \mathrm{A}$ & $23(23.0)$ & $167(82.3)$ \\
\hline & & $\mathrm{G} / \mathrm{G}+\mathrm{A} / \mathrm{G}$ & $77(77.0)$ & $167(82.3)$ \\
\hline & & \multicolumn{3}{|c|}{$1.23(0.85-1.78)$} \\
\hline \multicolumn{5}{|l|}{ Polimorfismo } \\
\hline \multirow{9}{*}{$\begin{array}{l}X R C C 1 \\
\text { (rs25487) }\end{array}$} & Dominant & $\mathrm{T} / \mathrm{T}$ & $46(46.0)$ & $98(48.3)$ \\
\hline & OR (CI95\%) & $\mathrm{T} / \mathrm{C}+\mathrm{C} / \mathrm{C}$ & $54(54.0)$ & $105(51.7)$ \\
\hline & & \multicolumn{3}{|c|}{$0.94(0.68-1.29)$} \\
\hline & Codominant & $\mathrm{T} / \mathrm{C}$ & $38(38.0)$ & $79(38.9)$ \\
\hline & OR(CI95\%) & $\mathrm{T} / \mathrm{T}+\mathrm{C} / \mathrm{C}$ & $62(62.0)$ & $124(61.1)$ \\
\hline & & \multicolumn{3}{|c|}{$0.9744(0.69-1.35)$} \\
\hline & Recessive & $\mathrm{C} / \mathrm{C}$ & $16(16.0)$ & $26(12.8)$ \\
\hline & OR (CI95\%) & $\mathrm{T} / \mathrm{T}+\mathrm{T} / \mathrm{C}$ & $84(84.0)$ & $177(87.2)$ \\
\hline & & \multicolumn{3}{|c|}{$1.18(0.77-1.80)$} \\
\hline \multicolumn{5}{|l|}{ Polimorfismo } \\
\hline \multirow{9}{*}{$\begin{array}{l}\text { RTEL1 } \\
\text { (rs6010620) }\end{array}$} & Dominant & $\mathrm{A} / \mathrm{A}$ & $0(0.0)$ & $0(0.0)$ \\
\hline & OR (CI95\%) & $\mathrm{A} / \mathrm{G}+\mathrm{GG}$ & $100(100.0)$ & $203(100.0)$ \\
\hline & & & $\mathrm{N} / \mathrm{C}$ & \\
\hline & Codominant & $\mathrm{A} / \mathrm{G}$ & $99(99.0)$ & $203(100.0)$ \\
\hline & OR (CI95\%) & $\mathrm{A} / \mathrm{A}+\mathrm{G} / \mathrm{G}$ & $1(1.0)$ & $0(0.0)$ \\
\hline & & \multicolumn{3}{|c|}{$0.32(0.27-0.38)$} \\
\hline & Recessive & $\mathrm{G} / \mathrm{G}$ & $1(1.0)$ & $0(0.0)$ \\
\hline & OR (CI95\%) & $\mathrm{A} / \mathrm{A}+\mathrm{A} / \mathrm{G}$ & $99(99.0)$ & $203(100.0)$ \\
\hline & & \multicolumn{3}{|c|}{$3.05(2.59-3.58)$} \\
\hline
\end{tabular}

*Chi-Square and Fischer's Tests with significance level of $\mathrm{P}<0.05$; SG, Study Group; CG, Control Group; N, number of individuals; Abs. Freq, Absolute Frequency; CCND1, Cyclin D1; XRCC1, X-ray repair cross complementing group 1; RTEL1, Regulator of telomere elongation helicase $1 ;$ NC, Not Calculated.

\section{Discussion}

In this study, clinical profiles, lifestyle habits, comorbidities and survival of patients with gliomas and controls were evaluated, as well as their association with genetic variants involved in cell cycle regulation $(C C N D 1)$,
DNA single-strand break repair $(X R C C 1)$ and stability, protection and elongation of telomeres $(R T E L 1)$. For lifestyle habits, smoking stood out in patients with gliomas $(40.0 \%)$, confirming its relationship with brain tumors. The same occurred in meta-analysis studies showing that cigarette compounds are able to cross the blood brain

Table 3. Frequency of Histological Classifications, Distributed According to the Genotypes of CCND1-rs9344; $X R C C 1$-rs25487 and RTEL1-rs601620 in Patients with Gliomas

\begin{tabular}{lccccccccc}
\hline Histological Type & \multicolumn{2}{c}{ CCND1-rs9344 $(\mathrm{N}=100)$} & \multicolumn{2}{c}{ XRCC1-25478 (N=100) } & \multicolumn{3}{c}{ RTEL1-601620 (N=100) } \\
& $\mathrm{AA}$ & $-\mathrm{G}$ & $\mathrm{p}$ & $\mathrm{TT}$ & $-\mathrm{C}$ & $\mathrm{P}$ & $\mathrm{AA}$ & $-\mathrm{G}$ & $\mathrm{P}$ \\
& $\mathrm{N}(\%)$ & $\mathrm{N}(\%)$ & & $\mathrm{N}(\%)$ & $\mathrm{N}(\%)$ & & $\mathrm{N}(\%)$ & $\mathrm{N}(\%)$ & \\
\hline Grade I N=7 & $0(0)$ & $7(100)$ & 0.1858 & $3(43)$ & $4(57)$ & 0.9269 & $0(0)$ & $7(100)$ & $\mathrm{N} / \mathrm{C}$ \\
Grade II N=7 & $1(14)$ & $6(86)$ & 0.6696 & $5(71)$ & $2(29)$ & 0.2428 & $0(0)$ & $7(100)$ & $\mathrm{N} / \mathrm{C}$ \\
Grade III N=18 & $6(33)$ & $12(67)$ & 0.7897 & $10(56)$ & $8(44)$ & 0.524 & $0(0)$ & $18(100)$ & $\mathrm{N} / \mathrm{C}$ \\
Grade IV N=68 & $21(31)$ & $47(69)$ & 0.4858 & $28(41)$ & $40(59)$ & 0.2318 & $0(0)$ & $68(100)$ & $\mathrm{N} / \mathrm{C}$ \\
\hline
\end{tabular}

${ }^{*}$ Chi-Square and Fischer's Tests with significance level of $\mathrm{P}<0.05$; CCND1, Cyclin D1; XRCC1, X-ray repair cross complementing group 1; RTEL1, Regulator of telomere elongation helicase 1; NC, Not Calculated. 
Table 4. Distribution of Allele Frequencies of the Polymorphism of CCND1-rs9344; XRCC1-rs25487 and RTEL1-rs601620 in Patients with Gliomas (SG) and Individuals without the Disease (CG).

\begin{tabular}{|c|c|c|c|c|}
\hline \multirow[t]{2}{*}{ Polimorfismo } & \multirow[t]{2}{*}{ Allele } & \multicolumn{2}{|c|}{ Freq. Abs } & \multirow[t]{2}{*}{ p-value } \\
\hline & & SG & CG & \\
\hline \multirow[t]{2}{*}{$C C N D 1$} & $\mathrm{G}$ & $113(0.56)$ & $232(0.57)$ & 0.9497 \\
\hline & A & $87(0.44)$ & $174(0.43)$ & \\
\hline \multirow[t]{2}{*}{$X R C C 1$} & $\mathrm{~T}$ & $130(0.65)$ & $275(0.68)$ & 0.5616 \\
\hline & $\mathrm{C}$ & $70(0.35)$ & $131(0.32)$ & \\
\hline \multirow[t]{2}{*}{ RTEL1 } & A & $99(0.49)$ & $203(0.50)$ & 0.9766 \\
\hline & $\mathrm{G}$ & $101(0.51)$ & $203(0.50)$ & \\
\hline
\end{tabular}

SG, Study Group; CG, Control Group; CCND1, Cyclin D1; XRCC1, $\mathrm{X}$-ray repair cross complementing group 1, RTEL1, Regulator of telomere elongation helicase 1

barrier (BBB) (Talacchi et al., 2013). BBB is responsible for maintaining brain homeostasis, blocking several endogenous and carcinogens substances in a selective manner (Talacchi et al., 2013). N-nitroso compounds and nicotine are some of the major carcinogens found in tobacco. They are able to modify various pathways, damaging endothelial function and cell proliferation and migration, causing the formation of tumors (Talacchi et al., 2013).

Alcohol consumption also prevailed in patients (47.0\%). Alcohol is an important neurotoxic, capable of generating several diseases over time through excessive consumption (Seliger et al., 2016). After alcohol ingestion, it is oxidized into acetaldehyde, which is a well-known toxic metabolite to the brain, as it has carcinogenic effect and leads to changes in gene expression, methylation and various other processes. Furthermore, alcohol metabolism generates reactive species oxygen, which plays an important role in brain tumorigenesis (Talacchi et al., 2013). It is still unclear if the excessive use of alcohol is related to gliomas. Studies have confirmed the relationship between alcohol consumption and some cancers, such as pharynx, larynx, esophagus, liver, colon, rectum and breast. However, an association with gliomas has not been found so far (Talacchi et al., 2013).

Among all comorbidities, SAH was more frequent in patients with glioma $(55.0 \%)$, similar to the findings in a Dutch population (Wu et al., 2016). There is a scant relation between SAH and risk factor for glioma, particularly in the Brazilian population, with no reports in the literature. Several hypotheses may explain the higher SAH prevalence in patients with gliomas. Increased intracranial pressure or compression of the brain stem caused by the growth and expansion of tumors can be pointed out, which may cause SAH. Admittedly, high-grade gliomas produce cytokines and vasoactive substances related to angiogenesis and vascular remodeling (Mandelzweig et al., 2009).

In this study, DM prevailed in patients with gliomas $(22.0 \%)$, corroborating the findings of a North American study (Houben et al., 2004). This disease affects more than 246 million people worldwide and is associated with several types of cancer, such as liver, pancreas,

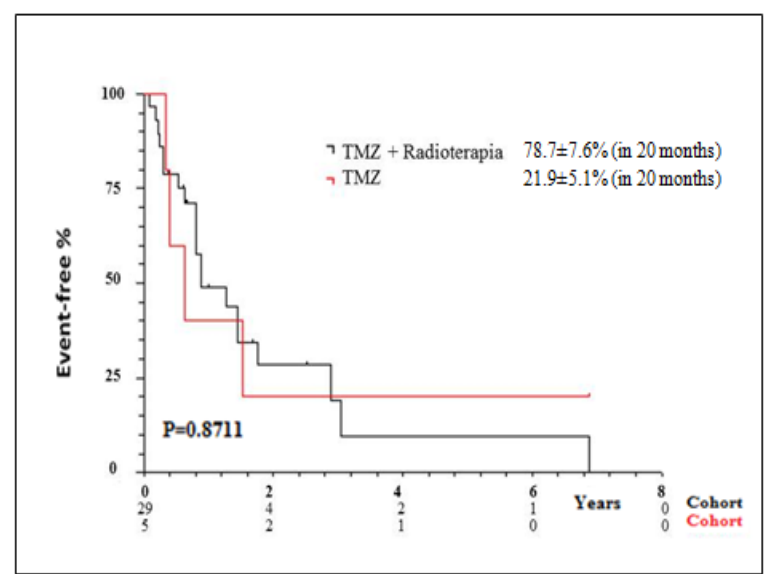

Figure 3. Kaplan-Meier Curve for the Analysis of Even-Free Survival (Death) in Patients with Gliomas who Received Temozalamide and Radiation Therapy

endometrium, breast and bladder (Chen et al., 2015). Studies have shown that hyperglycemia causes increased mortality and morbidity in many diseases in the acute phase (Kitahara et al., 2014). In this case, it can be related to tumor growth, as glucose is one of the major substrates of cerebral metabolism. Also, high-grade brain tumors have a high consumption of glucose, thus DM is related to short survival in patients with gliomas (Zhao et al., 2016). However, there are few studies that correlate this comorbidity to gliomas. In vitro studies have shown high rates of hyperglycemia associated with glioblastoma cells, but when glucose is removed, there was significant increase in apoptosis rates (Derr et al., 2009).

Noteworthy, obesity is associated with approximately $20 \%$ of all cases of cancer (Zhao et al., 2016). In this study, there was no association of overweight or obesity with gliomas; on the other hand, high body mass index in adulthood has been linked to increased risk of the disease, showing that negative energy balance can contribute to the development of brain tumors (Houben et al., 2004). In a meta-analysis of 22 studies including meningiomas and gliomas, overweight shows a substantial increased risk for both tumor types (Kitahara et al., 2014). However, in another meta-analysis, the relationship between overweight or obesity and gliomas could not be confirmed (Zhao et al., 2016). This study found no association between genotype and allele frequencies of the polymorphisms of CCND1 (rs9344), XRCC1 (rs25487) and RTEL1 (rs6010620) with gliomas, supporting several studies conducted with Chinese and Caucasian populations (Sergentanis et al., 2015). A casuistic study can also not be done in association of cyclin D1 with gliomas (Aytekin et al., 2014). On the other hand, there are references of the association between polymorphism and thyroid and breast cancer ((Jeon et al., 2018; Thakur et al., 2018), however the scarce ones are studies in Brazilian population. Cyclin D1, encoded by the CCND1 gene, is an important regulatory protein of the $\mathrm{G} 1$ phase transition to a phase of the cell cycle and has a great impact on the control of cell proliferation and differentiation (Zhang et al., 2011). In this case, SNPs may alter the function and function of $C C N D 1$, thus causing differences in individual 
susceptibility to cancer progression (Zhang et al., 2011).

For XRCC1, this study corroborates a study in Brazilian and Chinese casuistry (Wei et al., 2013; Fan et al., 2016). However, a meta-analysis by Han (2013) suggested that the XRCC1 Arg399Gln polymorphism was associated with a significant increase in the risk of glioma in Asians, but not in Caucasians, indicating a possible role of ethnic differences between genetics and the environment in who live. The protein synthesized by the $X R C C 1$ gene acts as a crucial role in the base excision repair (BER) pathway, its function is to repair damage caused by breaks of single strands of DNA, arising from internal and external factors such as exposure to ionizing radiation and alkylating agents, resulting in genetic stability and, consequently, increased risk for glioma (Wei et al., 2013; Liu et al., 2016). Genetic variants involving changes in amino acid sequences may alter $X R C C 1$ function, reducing repair kinetics in some individuals.

In relation to RTEL1, which encodes an enzyme known as DNA helicase, it plays a crucial role in regulating the length of telomeres (Melin et al., 2017). The maintenance and repair of DNA telomeres are essential processes that prevent genome instability and cancer (Vannier et al., 2014). Therefore, loss of RTEL1 function induces shortening of telomeres and chromosomal breaks. Helicase is a key protein in the repair of single-strand breaks, by direct involvement in the repair (DSB) of the English double-strand break (Du et al., 2014). However, in this study the RTEL1-rs6010620 polymorphism showed no association with gliomas, corroborating a study in North American cases (Lee et al., 2011). On the other hand, there is reference of this gene for susceptibility to glioma in French and Chinese cases, which may also suggest a relation between ethnicity and variants of RTEL1 (Hou et al., 2012; Di Stefano, et al., 2013). It is worth noting the novelty of the study of this polymorphism in Brazilian cases with gliomas.

In relation to the survival analysis of all patients, this study showed that on average $18 \%$ of patients are free of death event in three years, corroborating the findings of other findings (Galeone et al., 2013). Furthermore, even with aggressive treatment, 3-5 year mortality rate is higher than 95\% (Oudard et al., 1996). The analysis of the survival curve for the polymorphisms of CCND1, XRCC1 and RTEL1 showed reduced survival, although without statistical significance in the presence of the respective risk alleles of these polymorphisms. These findings are similar to the studies in other populations (Zhao et al., 2014; Adeberg et al., 2015). It is noteworthy that studies which related these polymorphisms to survival of patients with gliomas are quite rare in the literature and pioneer in the Brazilian population. Studies show that polymorphisms of CCND1, XRCC1 and RTEL1 and patients' survival are related to other types of cancer, such as lung, pharynx and larynx cancers (Walsh et al., 2013).

In this study, increased survival in patients receiving combined chemotherapy with Temozolamide (TMZ) and radiation therapy (RT) could also be observed. The same was found in a review study, which found that TMZ+ RT are able to prolong survival of patients with glioma (Zeybek et al., 2013). Admittedly, the post-surgical treatment of patients with glioblastoma and anaplastic astrocytoma is rather worrying, with survival rate at about six months (Zeybek et al., 2013). TMZ + RT are an important therapy, causing glioma cells death via autophagy through the combination of mTOR inhibitors (enhancers or autophagy). Radiation modulation or TMZ-induced autophagic response is one of the most promising approaches to prolong survival and understand high-grade gliomas (Zeybek et al., 2013).

Logistic regression analysis, with all variables, was more likely to belong to the group with gliomas, with the following characteristics: alcohol consumption and SAH. Importantly, these variables are possible predictors of the disease, corroborating the findings of another study (INCA et al., 2016).

In this study, polymorphisms involved in cell cycle $(C C N D 1)$, DNA repair $(X R C C 1)$ and protection and stability of telomeres (RTEL1) are not associated with gliomas. On the other hand, lifestyle habits and comorbidities are associated with gliomas, especially alcohol consumption and $\mathrm{SAH}$, as independent risk factors for the development of the disease. Low-grade gliomas, response to treatment and the combination of chemotherapy and radiotherapy shows increased survival of patients.

\section{Acknowledgements}

We would like to thank the Department of Pathology and Neurology of the Base Hospiatal, the School of Medicine of São José do Rio Preto, the Nucleus of Research in Biochemistry and Molecular Biology and to all who participated in the study.

\section{Funding Statement}

This work was supported by Fundação de Apoio à Pesquisa e Extensão de São José do Rio Preto - FAPERP, including Grant number: 025/2016; Fundação de Apoio à Pesquisa e Extensão de São José do Rio Preto - FAPERP. This work was supported by PIBIC / CNPq and the Medical School of São José do Rio Preto-FAMERP by the Scientific Initiation Scholarships.

\section{References}

Adeberg S, Bernhardt D, Ben Harrabi S, et al (2015). Metformin influences progression in diabetic glioblastoma patients. Strahlenther Onkol, 191, 928-35.

Aytekin T, Aytekin A, Maralcan G, et al (2014). A cyclin D1 (CCND1) gene polymorphism contributes to susceptibility to papillary thyroid cancer in the Turkish population. Asian Pac J Cancer Prev, 15, 7181-5.

Chen YJ, Xie LJ, Zhuang YD, Guo SR (2015). Note of the methodological flaws in the paper entitled "Association between the G870A polymorphism of cyclin D1 gene and glioma risk". Tumour Biol, 36, 8267-8.

Di Stefano AL, Enciso-Mora V, Marie Y, et al (2013). Association between glioma susceptibility loci and tumor pathology defines specific molecular etiologies. Neuro Oncol, 15, $542-7$.

Derr RL, Ye X, Islas MU, et al (2009). Association between hyperglycemia and survival in patients with newly diagnosed 
glioblastoma. J Clin Oncol, 27, 1082-6.

Du SL, Geng TT, Feng T, et al (2014). The RTEL1 rs6010620 polymorphism and glioma risk: a meta-analysis based on 12 case-control studies. Asian Pac J Cancer Prev, 15, 10175-9.

Fan SC, Zhou JG, Yin JZ (2016). Investigation of the role of XRCC1 genetic polymorphisms in the development of gliomas in a Chinese population. Genet Mol Res, 15, doi:10.4238/gmr.15038268.

Galeone C, Malerba S, Rota M, et al (2013). A meta-analysis of alcohol drinking and the risk of brain tumours. Ann Oncol, 24, 514-23.

Han JC, Zhang YJ, Li XD (2015). Association between polymorphisms in the XRCC1 gene and the risk of non-small cell lung cancer. Genet Mol Res, 14, 12888-93.

Hou L, Jiang J, Liu B, et al (2016). Smoking and adult glioma: a population-based case-control study in China. Neuro Oncol, 18, 105-13.

Hou WG, Ai WB, Bai XG, et al (2012). Genetic variation in the EGFR gene and the risk of glioma in a Chinese Han population. PLoS One, 7, e37531.

Houben MP, Louwman WJ, Tijssen CC, et al (2004). Hypertension as a risk factor for glioma? Evidence from a population-based study of comorbidity in glioma patients. Ann Oncol, 15, 1256-60.

INCA (2016). Title of subordinate document. In: Estimativa 2016 Incidência de Câncer no Brasil. Instituto Nacional de Cancêr José Alencar Gomes da Silva. 2016. http://www.inca.gov. br/estimativa/2016/sintese-de-resultados-comentarios.asp. (2016, accessed 17 April 2016).

Jeon S, Kim Y, Jeong YM, et al (2018). CCND1 splice variant as a novel diagnostic and predictive biomarker for thyroid cancer. Cancers (Basel), 10, pii: E437.

Kitahara CM, Linet MS, Brenner AV, et al (2014). Personal history of diabetes, genetic susceptibility to diabetes, and risk of brain glioma: a pooled analysis of observational studies. Cancer Epidemiol Biomarkers Prev, 23, 47-54.

Lee JM, Yang SY, Yang PW, et al (2011). Polymorphism in epidermal growth factor receptor intron 1 predicts prognosis of patients with esophageal cancer after chemoradiation and surgery. Ann Surg Oncol, 18, 2066-73.

Liu N, Fei X, Shen Y, et al (2016). Correlation between XRCC1 Arg399Gln genetic polymorphisms and susceptibility to bladder cancer: a meta-analysis. Onco Targets Ther, 9, 579-86.

Mandelzweig L, Novikov I, Sadetzki S (2009). Smoking and risk of glioma: a meta-analysis. Cancer Causes Control, 20, 1927-38.

Melin BS, Barnholtz-Sloan JS, Wrensch MR, et al (2017). Genome-wide association study of glioma subtypes identifies specific differences in genetic susceptibility to glioblastoma and non-glioblastoma tumors. Nat Genet, 49, 789-94.

Oudard S, Arvelo F, Miccoli L, et al (1996). High glycolysis in gliomas despite low hexokinase transcription and activity correlated to chromosome 10 loss. Br J Cancer, 74, 839-45.

Salazar LA, Hirata MH, Cavalli SA, Machado MO, Hirata RD (1998). Optimized procedure for DNA isolation from fresh and cryopreserved clotted human blood useful in clinical molecular testing. Clin Chem, 44, 1748-50.

Seliger C, Ricci C, Meier CR, et al (2016). Diabetes, use of antidiabetic drugs, and the risk of glioma. Neuro Oncol, 18, 340-9.

Sergentanis TN, Tsivgoulis G, Perlepe C, et al (2015). Obesity and risk for brain/CNS tumors, gliomas and meningiomas: A meta-analysis. PLoS One, 10, e 0136974.

Talacchi A, Hasanbelliu A, Fasano T, Gerosa M (2013). Interhemispheric approach to tumors of the posterior gyrus cinguli. Clin Neurol Neurosurg, 115, 597-02.
Thakur N, Kumari S, Mehrotra R (2018). Association between Cyclin D1 G870A (rs9344) polymorphism and cancer risk in Indian population: meta-analysis and trial sequential analysis. Biosci Rep, 38, pii: BSR20180694.

Vannier JB, Sarek G, Boulton SJ (2014). RTEL1: functions of a disease-associated helicase. Trends Cell Biol, 24, 416-25.

Wang X, Zhang H, Wang D, Li X (2015). Association of genetic polymorphisms of EGFR with glioma in a Chinese population. Genet Test Mol Biomarkers, 19, 59-2.

Walsh KM, Rice T, Decker PA, et al (2013). Genetic variants in telomerase-related genes are associated with an older age at diagnosis in glioma patients: evidence for distinct pathways of gliomagenesis. Neuro Oncol, 15, 1041-7.

Walsh KM, Ohgaki H, Wrensch MR (2016). Epidemiology. Handb Clin Neurol, 134, 3-18.

Wei X, Chen D, Lv T (2013). A functional polymorphism in $\mathrm{XRCC} 1$ is associated with glioma risk: evidence from a meta-analysis. Mol Biol Rep, 40, 567-72.

Wu Q, Peng Y, Zhao X (2016). An updated and comprehensive meta-analysis of association between seven hot loci polymorphisms from eight GWAS and glioma risk. $\mathrm{Mol}$ Neurobiol, 53, 4397-05.

Zeybek U, Yaylim I, Ozkan NE, et al (2013). Cyclin Dl gene $G 870 A$ variants and primary brain tumors. Asian Pac J Cancer Prev, 14, 4101-6.

Zhang LQ, Huang XE, Wang J, et al (2011). The cyclin D1 G870A polymorphism and colorectal cancer susceptibility: a meta-analysis of 20 populations. Asian Pac J Cancer Prev, 12, 81-5.

Zhang C, Lu Y, Zhang X, et al (2016). The role of the RTEL1 $r s 2297440$ polymorphism in the risk of glioma development: a meta-analysis. Neurol Sci, 37, 1023-31.

Zhang H, Liu Y, Zhou K, et al (2016). Genetic variations in the homologous recombination repair pathway genes modify risk of glioma. J Neurooncol, 126, 11-7.

Zhao L, Zheng Z, Huang P (2016). Diabetes mellitus and the risk of glioma: a meta-analysis. Oncotarget, 7, 4483-9.

Zhao W, Bian Y, Zhu W, Zou P, Tang G (2014). Regulator of telomere elongation helicase 1 (RTEL1) rs6010620 polymorphism contribute to increased risk of glioma. Tumour Biol, 35, 5259-66.

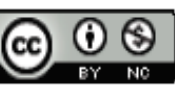

This work is licensed under a Creative Commons AttributionNon Commercial 4.0 International License. 